\title{
DESIGN AND PROCESS PLANNING OF MICRO GEAR MANUFACTURING
}

\author{
Suraj Kumar Sharma ${ }^{1}$,Prashant Mohan Trivedi' ${ }^{2}$, Sourabh Gupta ${ }^{3}$ \\ ${ }^{I}$ M.Tech. Mechatronics Department, Vellore Institute of Technology, Vellore, Tamil Nadu, India \\ ${ }^{2}$ M.Tech. Electronics \& Communication Department, SRM University, Chennai, India \\ ${ }^{3}$ B.E. Mechanical Engineering Department, B.I.S.T, Bhopal, Madhya Pradesh, India
}

\begin{abstract}
Today a large no of microstructures are already employed as separate components or as constituents of large modules in a broad spectrum of production in medical technology, optics, biotech, mechatronics, fluidics, micro forming and tool constitution. Current research activities are directed towards the downscaling of manufacturing procedures or the formation of complex process chains for the manufacturing of the micro workpieces in this paper we are going to design a micro gears and a suitable manufacturing process for making of micro gears. We are also going to study in detail various processing parameters and control technology of manufacturing micro gear by LIGA process. We are also going to design the micro gears or gear train using CATIA software.
\end{abstract}

Keywords: LIGA, Microgear.

$* * *$

\section{INTRODUCTION}

A gear train is used for transmission of power from one gear to another as it can reduce the power transmission or it can also increase power transmission from one gear to another. In recent years different technology for microgear manufacture is developed but we are using Liga process for the gear manufacturing. Microgear has been made from nickel metal and by using UV- rays and then by using electroforming and chemical mechanical polishing. Micro sized gears are made of the durable metal for miniaturization and reliability improvement of various products for general purpose. In manufacturing its aim is to achieve highest level of safety and also the economical efficiency. In this paper a micro gear is designed for power transmission. The micro involutes profile gears with the shaft and the micro cases were fabricated by UV-LIGA technology. In manufacturing terms the aim is to achieve a high economic efficiency to satisfy industrial need. Micro metal powder injection molding ( $\mu$ MIM) is useful for producing micro-sized and microstructure parts, but measuring the accuracy of microgears manufactured by $\mu$ MIM has proved difficult. The is made to reduce the speed from 100000 RPM to 65000 RPM used to rotate the micro mirrors, so the speed reduction was important. Suitable gear sizes are obtained by gear design.

P Bley in 1993 proposed and experimented the LIGA process for manufacturing of microgears. He explained in detail the procedure. Material selection and process parameters, controls are discussed by Mohammad Gad-ElHaq in MEMS Handbook. James allan also explained these parameters and process in his Handbook. The steps or data related to process planning was not available anywhere the process planning is done in this paper.

\section{GEAR TRAIN DESIGN}

The micromotors used to run the MEMS devices usually do not have exactly the same torque and speed required for the device.

In order to get these required conditions microgears are used. Let us consider following example to get a general idea about microgear design. Same methodology what we follow for macrogears system we tried to employ for microgears.

The micromotor data as follows Input torque $=75 \mu \mathrm{NM}$

Input speed $\left(N_{1}\right)=100000 R P M$

These conditions are used as input for the pinion of microgear train

Number of teeth on pinion $\left(Z_{1}\right)=24$

Number of teeth on gear $\left(Z_{2}\right)=38$

Calculation of required power

Power $=2 \times \pi \times N_{1} \times T$

Power $=0.78 \mathrm{~W}$

$$
\text { Module } \left.(\mathrm{m})=\sqrt[3]{\left[\frac{60 \times 10^{6}}{\pi}\right.}\left\{\frac{\text { Power } \times \mathrm{cs} \times \text { fos }}{\mathrm{z}_{1} \times \mathrm{N}_{1} \times \mathrm{CV} \times \frac{\mathrm{b}}{\mathrm{m}} \times \frac{\mathrm{sut}}{3} \times \mathrm{y}}\right\}\right]
$$

$\mathrm{m}=0.01 \mathrm{~mm}$

Diameter of pinion $\left(d_{p}\right)=Z_{1} \times m=0.240 \mathrm{~mm}$

Diameter of gear $\left(d_{g}\right)=Z_{2} \times \mathrm{m}=0.380 \mathrm{~mm}$ 
Force calculations:

Tangential load on teeth $=\frac{2 \times \text { torque }}{d_{p}}=0.15 \mathrm{~N}$

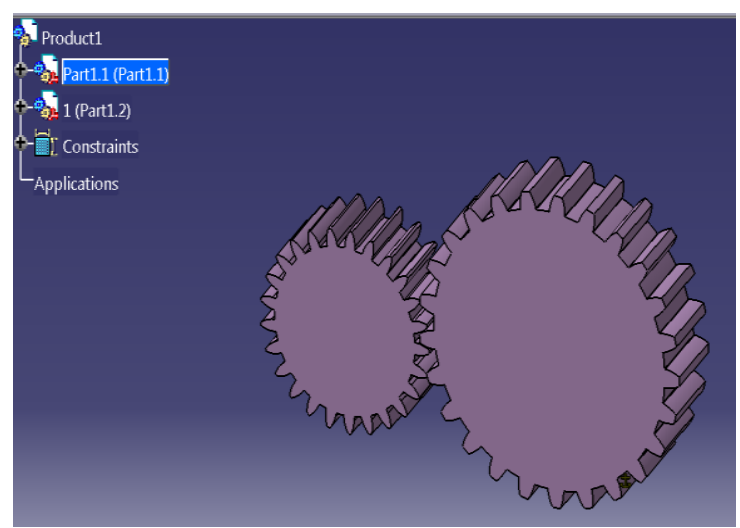

Fig.1. CATIA Model

\subsection{Scaling}

Two types of scaling laws are used. The first one is scaling in geometry. The second law involves the scaling of phenomenological behavior Microsystems.

The force calculated earlier is verified by applying the scaling law for microgear. The gear of same nickel material with diameter of $90 \mathrm{MM}$ is reduced to $0.240 \mathrm{MM}$. thus, the scaling factor is 375 .

As the diameter is reduced the order of scaling is 1 . For this order the scaling factor or reduction in force is L (i.e. 375). The tangential force on macrogear was $1433 \mathrm{~N}$ is reduced to $4 \mathrm{~N}$ for microgear. The calculated force is well within limits.

\section{MANUFACTURING PROCESS}

LIGA is acronym for the Germen terms Lithography (Lithographie), electroforming (Galvanoformung), and molding (Abformung).The technique was first developed at Karlsruhe Nuclear Research Center in Karlsruhe, Germany. LIGA is fabrication technology used to create high aspect microstructures. Generally in the LIGA process we are using deep X-ray lithography and electroforming. Some extension has been done in the process so that the number of application can be increased such as we are using the sacrificial technique used for producing moving micro scale structure and by using the patterned plastic with X-ray lithography and as well as moulding we can produced different shape with different type of dimensions so by improving the process we can used the LIGA process for different type of materials and for complex applications such as for microgears, micromotors, microturbines, micropumps.

The common steps involved in manufacturing of microgears using LIGA process are as follows

1. Substrate preparation

2. Application of photoresist on substrate surface

3. Mask preparation
4. Exposing the resist to ultraviolet light

5. Development of photoresist

6. Electroforming

7. Chemical Mechanical Polishing

There are various parameters associated with all of these above steps. Deciding the values of all these parameters gives the process plan for the manufacturing in detail.

Let us have a look on the parameters step by step.

1. Substrate preparation - In this phase we consider different parameters such as material, dimension of substrate. We have taken the silicon substrate of dimension $3 \mathrm{~mm} \times 3 \mathrm{~mm}$.Silicon has good conductivity and also results in the minimum of wastages.

2. Application of photoresist-In this phase we consider different parameters such as type of photoresist applied and thickness of layer. We have applied positive photoresist and used PMMA (poly methyl metharcylate) and height of PMMA layer applied is $300 \mu \mathrm{m}$.

3. Mask- During this step we consider different parameters such as mask material and thickness or height of mask. We have taken Beryllium with height of $30 \mu \mathrm{m}$ or we can take also $3 \mu \mathrm{m}$ height titanium layer with gear geometry hole in it.

4. Exposure to UV-During this phase we have to consider different parameters such as UV light sources such as mercury vapor lamp, Deep UV light, normal UV light and wavelength of UV light We have consider positive photoresists are sensitive to light with wavelength of 300 to $500 \mathrm{~nm}$. We have taken normal UV rays.

5. Development of photoresist-In this phase we have consider parameters like solvent type, solvent rate. Here we can take Tetra methyl ammonium hydroxide(TMAH),Potassium hydroxide( $\mathrm{KOH})$ and this solvent work for positive photoresist as (chemical reaction+solubility for resist).For negative photoresist only a solubility action develops the resist.

6. Electroforming-During this we have to consider different parameters such as type of material used in electroforming as in this process the material is used for filling the gear hole to give the gear shape. Here $\mathrm{Fe}-\mathrm{Ni}$ is used as this alloy has low thermal coefficient and high surface hardness.

7. Chemical mechanical polishing-In this process we are doing smoothing of surface with combination of different forces such as chemical and mechanical forces. A typical Chemical mechanical polishing tool consists of the rotating and extremely flat platen which is covered by pad. This process uses different type of chemical slurry like abrasive and chemical known as (Colloid) is supported with the polishing pad and retaining ring which has the greater diameter than wafer. The wafer and pad combine or pressed together by a dynamic polishing head and 
held by plastic ring. This dynamic polishing head rotated with the different axis of rotation.

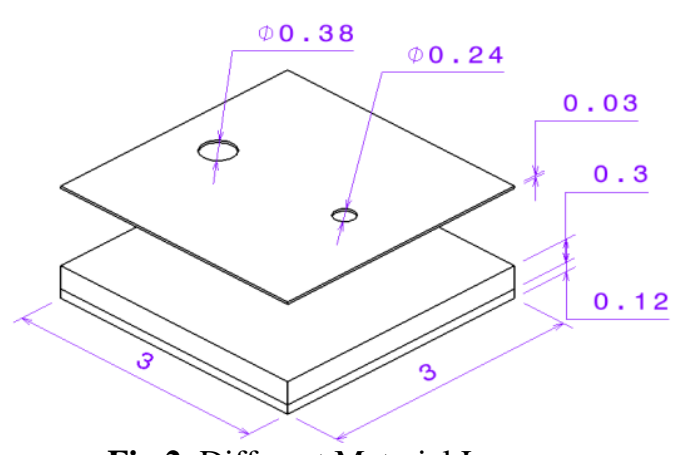

Fig.2. Different Material Layers

\section{PROCESS PLAN}

\begin{tabular}{|c|c|c|c|}
\hline $\begin{array}{l}\text { Step } \\
\text { numbe } \\
\mathbf{r}\end{array}$ & Description & Parameters & $\begin{array}{l}\text { Selected } \\
\text { values }\end{array}$ \\
\hline 1 & $\begin{array}{l}\text { Substrate } \\
\text { preparation }\end{array}$ & $\begin{array}{l}\text { 1.Material } \\
\text { 2.Dimension } \\
\text { 3.Number of } \\
\text { substrates }\end{array}$ & $\begin{array}{l}3 \mathrm{~mm} \quad \times \\
3 \mathrm{~mm} \\
\text { Silicon } \\
\text { substrate. } \\
\text { Single } \\
\text { substrate }\end{array}$ \\
\hline 2 & $\begin{array}{l}\text { Application } \\
\text { of } \\
\text { photoresist }\end{array}$ & $\begin{array}{l}\text { 1.Material } \\
\text { 2.Thickness } \\
\text { of layer }\end{array}$ & $\begin{array}{l}\text { Positive } \\
\text { photoresi } \\
\text { st } \\
\text { (PMMA) } \\
\text { Thickness } \\
0.300 \mathrm{~mm}\end{array}$ \\
\hline 3 & $\begin{array}{l}\text { Mask } \\
\text { preparation }\end{array}$ & $\begin{array}{l}\text { 1.Type } \\
\text { 2.Thickness }\end{array}$ & $\begin{array}{l}\text { Beryllium } \\
\text { with } 30 \\
\text { microns } \\
\text { thickness }\end{array}$ \\
\hline 4 & $\begin{array}{l}\text { Exposure to } \\
\text { UV light }\end{array}$ & $\begin{array}{l}\text { 1.Type of } \\
\text { source } \\
2 . \text { Wavelengt } \\
\text { h suitable for } \\
\text { the resist }\end{array}$ & $\begin{array}{l}\text { UV light } \\
300- \\
500 \mathrm{~nm} \\
\text { waveleng } \\
\text { th }\end{array}$ \\
\hline 5 & $\begin{array}{l}\text { Developme } \\
\mathrm{nt}\end{array}$ & $\begin{array}{l}\text { 1.Solvent } \\
\text { type }\end{array}$ & $\begin{array}{l}\text { TMAH or } \\
\mathrm{KOH}\end{array}$ \\
\hline 6 & $\begin{array}{l}\text { Electroform } \\
\text { ing }\end{array}$ & $\begin{array}{l}\text { 1.Type of } \\
\text { material }\end{array}$ & Nickel \\
\hline 7 & $\begin{array}{l}\text { Chemical } \\
\text { Mechanical } \\
\text { Polishing }\end{array}$ & $\begin{array}{l}\text { 1.Type of } \\
\text { abrasive } \\
\text { slurry }\end{array}$ & Colloid \\
\hline
\end{tabular}

Cleanliness and preparation of substrates is essential for success in thin film work. Condensation rate and adhesion of the deposit are critically dependent of conditions on the surface. Even a thin layer of grease can have such a gross effect on a molecular scale as to alter completely the characteristics of the layer.

Where possible substrates and optical components are cleaned in an ultrasonic bath with an alkali based cleaner. Then are they rinsed in hot water and submerged in isopropyl alcohol to prevent water marks. Drying and dust removal finally makes them ready for the coating process. Any slight marks found on the substrates mean that the whole process must be repeated. After cleaning, the items are secured in special jigs, this stops any movement of the piece and vibration from the coating plant affecting the coating. Any jigs that are not held in house are manufactured when required.

In the first step, the wafers are chemically cleaned to remove particulate matter on the surface as well as any traces of organic, ionic, and metallic impurities. After cleaning, silicon dioxide, which serves as a barrier layer, is deposited on the surface of the wafer. After the formation of the $\mathrm{SiO} 2$ layer, photoresist is applied to the surface of the wafer. High-speed centrifugal whirling of silicon wafers is the standard method for applying photoresist coatings in Gear manufacturing. This technique, known as "Spin Coating," produces a thin uniform layer of photoresist on the wafer surface.

One of the most important steps in the photolithography process is mask alignment. A mask or "photomask" is a square glass plate with a patterned emulsion of metal film on one side. The mask is aligned with the wafer, so that the pattern can be transferred onto the wafer surface. Each mask after the first one must be aligned to the previous pattern.

Once the mask has been accurately aligned with the pattern on the wafer's surface, the photoresist is exposed through the pattern on the mask with a high intensity ultraviolet light.

In contact printing, the resist-coated silicon wafer is brought into physical contact with the glass photomask. The wafer is held on a vacuum chuck, and the whole assembly rises until the wafer and mask contact each other. The photoresist is exposed with UV light while the wafer is in contact position with the mask. Because of the contact between the resist and mask, very high resolution is possible in contact printing (e.g. 1-micron features in 0.5 microns of positive resist). The problem with contact printing is that debris, trapped between the resist and the mask, can damage the mask and cause defects in the pattern.

Electroforming is the highly specialised use of electrodeposition for the manufacture of metal parts. The metals that can be electroformed successfully are copper, nickel, iron or silver, thickness up to $16 \mathrm{~mm}$, dimensional tolerances up to $1 \mathrm{pm}$, and surface finishes of $0.05 \mathrm{pm} \%$. The ability to manufacture complex parts to close tolerances and cost effectively has meant that electroforming has applications both in traditional/macro manufacturing and new micromanufacturing fields. These include tooling; mould making; fabrication of microelectromechanical systems (MEMS) and the combination of lithography, electroforming and plastic moulding in the LlGA process.

CMP processes produce both global and local planarization through relatively simple and quick processing. The mechanical energy imparted to the abrasive slurry particle through pressureand rotation causes high features to erode at 
a faster rate than low features, thereby planarizing the surface over time.

\section{PART HANDLING SYSTEM}

As the handling of gear is most difficult due to size in the microns so it requires the special type of handling system. For microgear we do part handling by the horizontal operating MULTILIFT $\mathrm{H}$ robotic system. In this type of handling system vacuum grippers is used for microgear handling. Different types of vacuum circuit are used for grippers and discharge functions. The robotic system is generally of high performance linear robotic system which has the features such as compact design and very high level of flexibility Different type of microgear can be handled by varying axes, axis lengths and axis drives of linear robot. The vertical MULTILIFT V features a very large area due to different gripper connection option we can reliably implement any insertion and removal task. The machine and robotic system can be programmed by the graphic symbols of SELOGICA using interface.

\section{Features of Robotic System-}

Flexible parts handling: individual axis configuration and freely programmable pick-up and set-down patterns.

Reduce the cycle time to great extent due to freely movement which is programmable and the movements are simultaneously.

Due to interactive tech-in function short set up times.

The SELOGICA control panel which is portable and touch screen enables fast machine and robotic system set-up.

\section{RESULT}

The input speed is reduced from 100000 RPM to 65000 RPM.

The detailed process planning is given. The parameters required to make the process plan were studied.

The module was calculated and found to be $0.01 \mathrm{~mm}$. The tangential force acting on the tooth was also calculated and found to be within limits.

\section{CONCLUSIONS}

There are no repair or rework techniques available to reduce the rejection of microparts manufactured by LIGA process, hence detailed process planning is required.

The micro gears are designed by same empirical formulae as macro gear only scaling has to be considered.

The microgears cannot be manufactured by conventional machining processes and also the microgears are precision gears with very high accuracy and surface quality to achieve these requirements LIGA process is useful.
The possible defects may be caused by misalignments of the different layers, improper focusing of light care must be taken regarding these issues.

The handling and vision systems must employed in assembling the parts.

\section{REFERENCES}

[1] A. Albers, N. Burkardt, J. Marz. Restriction in design of gear wheel components and drives of micro technology. Microsystem technologies 9(2003) 192-196 Springer-Verlag 2003.

[2] V. Hegadekatte, J. Hilgert, O. Kraft, N. Huber. Multi time scale simulations for wear prediction in microgear.Journal

homepage:www.elsevier.com/locate/wear.

[3] Mohammad Gad-El-Haq. (2001). The MEMS Handbook volume 2, Scaling laws (pp.274305).CRC Press.

[4] Dale L. Hetherington, Jeffry J. Sniegowski. Surfacemicromachined micromirror devices using chemicalmechanical polishing. Sandia National Laboratories, MS 1084 Albuquerque, NM 8715.

[5] James Allen. (2005). The MEMS Handbook. CRC Press.

[6] DR. P Bley. The Liga process for the fabrication of three-dimensional microstructures. Microsystem technology programmed, Karlsruhe Nuclear Research Centre (KFK) Germany.

[7] Seong Ho Son Sung Cheol, Park, Wonsil Lee, Hong-Kee Lee. Manufacturing of microgear by electroforming of $\mathrm{Fe}-\mathrm{Ni}$ and $\mathrm{Fe}-\mathrm{Ni}-\mathrm{W}$ alloys. Journal homepage: www.science.direct.com.

[8] Tai Ran Hsu (2002). MEMS and Microsystems: Design and manufacture. McGraw-Hill.

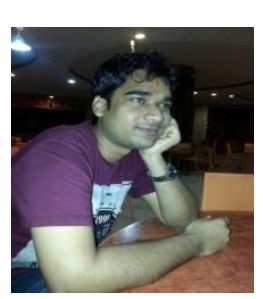

\section{BIOGRAPHIES}

Mr. Suraj Kumar Sharma has to his credit B.E. in Electronics \& Instrumentation from Chattisgarh Swami Vivekananda Technical University,Bhilai,Chattisgarh in 2012. As a part of his Master's (M.Tech.) in Mechatronics from VIT University, Vellore, Tamil Nadu, India, he is currently pursuing a six-month internship programme at TIFAC, New Delhi. His area of interest covers Robotics, Network Theory,Control System and Digital Logic design.

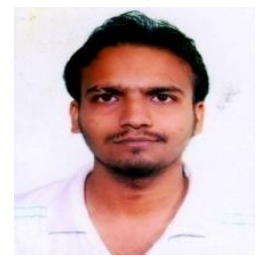

Mr.Prashant Mohan Trivedi has to his credit B.E. in Electronics \& Communication from Chattisgarh Swami Vivekananda Technical University,Bhilai,Chattisgarh in 2011.Presently, he is Pursuing Master's(M.Tech.) in Communication System from SRM University,Chennai,Tamil Nadu,India. His area of interest covers Signal Processing,Wireless Communication and Digital Logic design. 
Mr. Sourabh Gupta has to his credit B.E. in Mechanical Engineering from Bansal Institute of Science and Technology, Bhopal,Madhya Pradesh in 2014. His area of interest covers Industrial

DEVIICW Engineering and Machine Design. 